\title{
Representation of memory processes by verbal collocations with the semantic component "time"
}

\section{[Репрезентация процессов памяти глагольными коллокациями с семантическим компонентом «время»]}

\author{
Larisa Rebrina
}

DOI: $10.18355 / X L .2019 .12 .03 .19$

\begin{abstract}
The article investigates the structural, semantic and syntagmatic characteristics of the memory verbal collocations of the German language with the semantic component "time," extracted on the basis of statistical parameters from the newspaper corps of DWDS. The key words are the nouns Vergangenheit (past), Gegenwart (present), Zeit (time), Ewigkeit (eternity), characterized by high syntagmatic potential, indicating the significance of the corresponding concepts for the mental and linguistic representation of memory operations. The component composition of collocations, the structure of the internal organization of the lexical set, the meanings of case forms of nominal components, objectness and subjectness, external or internal transitivity / intransitivity, structural and semantic models, thematic codes, collocation series, pragmatic components of the semantics of word combinations are described. The complex of semasiologically and onomasiologically oriented methods of analysis allows to obtain polyaspectual information on collocations, to describe the elements of the linguistic model of memory, to draw conclusions about the peculiarities of the lexical-semantic representation by the statistically stable consisting of more than one word units of the memory phenomenon in the context of its connection with time. The results are of practical importance for the automatic processing of texts, linguodidactics, translation, ideographic lexicography.
\end{abstract}

Key words: verb collocations, memory, time, representation, syntagmatics, semantics, German media, corpus, lexico-semantic representation

\section{Аннотация}

В статье исследуются структурные, семантические и синтагматические характеристики глагольных коллокаций памяти немецкого языка с семантическим компонентом «время», извлеченные на основе статистических параметров из газетных корпусов DWDS. Ключевыми словами выступают существительные Vergangenheit (прошлое), Gegenwart (настоящее), Zeit (время), Ewigkeit(вечность), характеризующиеся высоким синтагматическим потенциалом, указывающим на значимость соответствующих понятий для ментального и языкового представления операций памяти. Описываются компонентный состав коллокаций, структура внутренней организации лексического множества, значения падежных форм именных компонентов, объектность и субъектность, внешняя или внутренняя переходность / непереходность, структурно-семантические модели, тематические коды, серии коллокаций, прагматические компоненты семантики словосочетаний. Комплекс семасиологически и ономасиологически ориентированных методов анализа позволяет получить полисапектную информацию о коллокациях, описать элементы лингвоментальной модели памяти, сделать выводы об особенностях лексико-семантической репрезентации неоднословными статистически устойчивыми единицами феномена памяти в контексте его связи со временем.

XLinguae, Volume 12, Issue 3, June 2019, ISSN 1337-8384, eISSN 2453-711X 
Результаты имеют практическую значимость для автоматической обработки текстов, лингводидактики, перевода, идеографической лексикографии.

Ключевые слова: глагольные коллокации, память, время, синтагматика, семантика, СМИ Германии, корпус, лексико-семантическая репрезентация

\section{Введение}

Тема работы сопряжена, во-первых, с изучением репрезентации в лексико-семантической системе немецкого языка памяти в ее взаимосвязи с понятиями о времени, во-вторых, с исследованием функционирования языка, в частности, синтагматических отношений, отражающихся в сочетаемости единиц данной системы.

Память как высшая психическая функция, играющая огромную роль в процессах адапциогенеза человека, обеспечивающая равновесие индивидуальной и коллективной психо- и инфосферы (Baddeley, 2007; Baumeister, 1997; Keppler, 2001), сопряжена с ключевыми философскими категориями (пространство, время, сознание) как «четвертое измерение», объективирующее модальность взаимоотношений между прошлым, настоящим и будущим. Память лежит в основе выделения и осмысления категорий пространства и времени, которые мы воспринимаем как некий объективный регулятив (Welzer, 2005: 116). Данные категории как некие конструкты (разновидности ощущений воспринимающего субъекта, основывающиеся на его способности запоминать и сравнивать образы) производны от памяти и информации при различающихся способах считывания последней. Движение / изменение объекта относительно неподвижного внимания дает ощущение времени, а подвижное внимание относительно неподвижного объекта ощущение пространства (Popov, Kraynyuchenko, 2009). При этом комплекс «пространство - время» является обусловливающим для памяти, так как параметры пространственно-временной структуры мира (последовательность, повторяемость, длительность) составляют в континууме воздействий необходимое условие отражения как основы памяти (AnokhinP.K, Anokhin K.V, 2011). Поэтому память является обязательным элементом Вселенной и любой ее теории (Bergson, 1992). С другой стороны, сама память, представляя собой социальный конструкт, интерпретативный и контекстуальный по своей природе, существует в собственном времени и пространстве (обнаруживающим особые свойства в противовес физическим коррелятам): мнемоническое время отличается повторяемостью и обратимостью, а мнемоническое пространство нелинейностью и семантической природой (Bakiyeva, 2001).

Особая актуальность проблематики памяти обусловливается сегодня и исключительной временной «уплотненностью» (Prigogine, Stengers, 1984), результирующей сокращение настоящего, и, как следствие, рост потребности в восстановлении и поддержании связи между настоящим и «расширяющимся» прошлым, в противодействии угрозе темпорального растворения личности (Lübbe, 2003: 106-108). Постоянное расширение исследовательской парадигмы памяти в языкознании обусловливается ее индивидуальной и социальной значимостью, сложностью и многомерностью, масштабными социальными изменения, коррелирующими с преобразованиями самой памяти, существенным эвристическим потенциалом лингвистики в данной области, объясняемым, прежде всего, дискурсивным характером, институализацией памяти, связью памяти с языком как средством ее конструирования и манифестации. Названная парадигма конституируется исследованиями семантических, морфологических характеристик отдельных лексических единиц (ЛЕ) / фрагментов семантического поля «Память»; конкретных дискурсивных практик, объективирующих функционирование разных подсистем памяти; связи памяти 
и речемыслительных механизмов; признаков концепта «память»; семиотики памяти (Н.Г. Брагина, Т.В. Булыгина, А.А. Зализняк, Б.Л. Иомдин, В.В. Туровкий, М.А. Дмитровская, О.Г. Ревзина, О.В. Щиленко и др.). Коллокации, под которыми нами понимаются статистически устойчивые, неслучайные сочетания ЛЕ, типичные для языка и для конкретного типа текстов, отражающие соответствующий узус (Э. Бялек, О.Л. Бирюк, В.Ю. Гусев, В.П. Захаров, М.В. Хохлова, Е.В. Ягунова, S. Evert, C. Manning, S. Petrovic, M. Stubbs и др.), представляют собой перспективный объект лексической синтагматики.

Результаты предпринятого исследования расширяют эмпирическую базу изучения лингвокультурной специфики лексико-семантической репрезентации памяти, корпусных исследований лексических подсистем языка и явления комбинаторности, могут найти практическое применение в идеографической лексикографии, автоматической обработке текстов, лингводидактике и переводе.

\section{Методология}

Концепция работы базируется на научных положениях о коммуникативной, социальной природе памяти и общих с языком семиотических механизмах памяти (Halbwachs, 2007; Daneman, 1991; Dias, 2010; Linke, 2005; McQuaid, 2017; Müller-Funk, 2004; Petrova A.A., Rebrina, 2016; Welzer, 2005; Wylegała, 2017); об уровневой семантической структуре и синтаксическом статусе глагольных ЛЕ (Gaysina, 1982); на имеющихся результатах лингвистических исследований этноспецифики репрезентаций памяти как денотата, фрагмента языковой картины мира и концептосферы (Bragina, 2003; Rebrina, Shamne, Milovanova, Terentyeva, 2017; Petrova, Rebrina, 2016]); ЛЕ вторичной номинации (Didkovskaya, 2000; Leontyeva, 2003; Zhakina, 2003); явления комбинаторности, коллокаций как единиц языка и объекта лексикографии (Byalek, 2004; Khokhlova, 2010; Yagunova, Pivovarova, 2010; Geyken, 2007; Elnitsky, Mel'cuk, 1984, Hausmann, 1985; Kilgarriff, 2006; Manning, Schutze, 2002; Petrovic, Snajder, Basic, Kolar, 2006).

Обобщив наблюдения, представленные в исследованиях в русле семантикосинтаксического подхода, британского контекстуализма, теории «Смысл↔Текст», термин «коллокация» в своей работе мы рассматриваем как родовой для статистически устойчивых словосочетаний. На фоне активной разработки методологии извлечения и лексикографического описания коллокаций, издания комбинаторных, толково-сочетаемостных и толковокомбинаторных словарей, словарей устойчивых сочетаний и коллокаций (О.Л. Бирюк， Е.Г. Борисова， П. Браславский， В.Ю. Гусев， А.К. Жолковский, В.П. Захаров, Е.Ю. Калинина, И.А. Мельчук, О.А. Митрофанова, B.B. Морковкин, S. Atkins, E. Benson, M. Benson, K. Church, S. Evert, F.J. Hausmann, R. Ilton, A. Kilgarriff, I.A. Mel'cuk, J. Sinclair и др.) задача идеографического представления коллокаций для характеристики предметной области остается нерешенной.

Корпусный менеджер дает возможность анализировать большие массивы языковых фактов, адаптировать критерии извлечения ЛЕ, использовать статистические параметры. Анализируемые глагольные коллокации памяти (ГКП) извлечены с учетом меры ассоциаций $\log D i c e$ из газетных корпусов немецкоязычной лингвистической платформы DWDS (DWDS) (82 ГКП с ключевыми словами Vergangenheit - прошлое, Zeit - время, Ewigkeit - вечность, Gegenwart - настоящее, обозначающими фрагменты временного континуума или весь континуум в целом).

XLinguae, Volume 12, Issue 3, June 2019, ISSN 1337-8384, eISSN 2453-711X 
Приведенные ключевые слова (КС) содержат в своем значении семантический компонент «время», по-разному членят данный континуум:

1) КС Vergangenheit (прошлое) акцентирует ретроспективный характер памяти («Zeit, die hinter uns liegt, vergangen ist; das Leben eines Menschen bis zum gegenwärtigen Zeitpunkt» (DWDS) - «время, которое находится позади, которое прошло; жизнь какого-либо человека до настоящего момента»);

2) КС Gegenwart (настоящее) акцентирует интенционально обусловленную актуальную значимость мнемических операций, реактуализацию объекта, наличие, присутствие или возвращение объекта мнемических действий в определенный момент времени в индивидуальное / коллективное сознание («Zeit, in der wir leben, Jetztzeit, Umgebung; Anwesenheit, Dasein» (DWDS) «время, в которое мы живем, теперешнее время, современность, окружение, присутствие, существование»);

3) KC Zeit (время) как родовое понятие указывает на потенциальную направленность мнемических ситуаций на любую произвольно вычленяемую часть временного континуума ( $« 1$. nur im Singular, Gesamtheit der ablaufenden Sekunden, Minuten, Stunden, Tage, Wochen, Jahre; Marxismus - Begriff, der die Dauer und die Aufeinanderfolge der materiellen Prozesse erfasst, grundlegende Existenzform der Materie, deren jeweilige Eigenschaften von der Beschaffenheit der Materie abhängen; 2. nur im Singular, Teil von 1, über den jmd. verfügen kann; 3. nur im Singular, bestimmte Stunde und Minute eines Tages, die von der Uhr angezeigt wird; 4. Zeitpunkt; 5. Zeitraum; 6. größerer Zeitraum innerhalb der geschichtlichen Entwicklung» (DWDS) - «1. только в ед.ч., совокупность протекающих секунд, минут, часов, дней, недель, лет; в марксизме - понятие, которое указывает на длительность и последовательность материальных процессов, основная форма существования материи, чьи свойства определяются свойствами материи; 2. только в ед. ч., часть того, что названо под номером 1, которая может быть в чьем-либо распоряжении; 3. только в ед. ч., определенный час или минута дня, который / которую показывают часы; 4. конкретный момент времени; 5. промежуток времени; 6. значительный промежуток времени в ходе исторического развития»);

4) КС Ewigkeit (вечность) указывает на весь нечленимый континуум, отражает с одной стороны проспективность, с другой стороны, потенциально вневременной характер памяти, ее сопряженность с неподвластным времени («1. zeitliche Unendlichkeit; 2. nur im Singular, dichterisch das Unvergängliche, Göttliche; 3. übertrieben, sehr lange Zeit» (DWDS) - «1. временная бесконечность; 2. только в ед. ч., поэтическое - непреходящее, божественное; 3. преувеличение - очень длительное время). Понятие «будущее» оказывается нерелевантным для обозначения мнемических процессов, соответствующий семантический компонент включается в лексико-семантическую репрезентацию памяти в той мере, в какой он входит в семантику КС Ewigkeit (вечность).

Компоненты анализируемых ГКП подвергаются определенному переосмыслению, что детерминирует синтагматические характеристики как компонентов коллокаций, так и самих ГКП. ГКП реализуют особый способ номинации операций памяти, в основе которого лежит допущение о подобии, способствующее наглядному представлению денотативных ситуаций и генерированию нового знания об объекте номинации. ГКП характеризуются осложненным способом выражения содержания, постоянным составом, ограниченной трансформируемостью, предметно-логической заданностью синтагматических связей, раскрывающейся во внутренней форме ГКП.

Частота совместной встречаемости и относительная линейная близость значимые факторы при извлечении глагольных коллокаций (Yagunova, Pivovarova, 2010). Мера ассоциаций $\log$ ice позволяет объединять ЛЕ в 
связанные, неслучайные сочетания благодаря учету ближайшего контекста, соотнесению частоты встречаемости КС совместно с коллокатом (разные глаголы) и совокупной частотности КС и коллоката в корпусе.

Посредством сочетания семасиологически и ономасиологически ориентированных методов анализа может быть получена полиаспектная информация о ГКП с КС с семантическим компонентом «время» (структурные, семантические, прагматические, синтагматические характеристики): количество компонентов и структура ГКП; значения падежных форм КС; субъектность (одно- и двусубъектность, то есть допустимость одушевленного / неодушевленного субъекта) или объектность коллокации; внутренняя / внешняя переходность / непереходность ГКП; активность КС при образовании серий коллокаций (ГКП, объединяемые в один ряд общим компонентом и способом языковой репрезентации представлений об операциях памяти); структурносемантические модели ГКП как схематизированные инварианты корреляции семантических и формальных характеристик коллокаций; тематические коды (сферы отождествления при номинации денотативных ситуаций как источники конкретных образов); прагматические признаки в семантической структуре единиц (субъективная оценка, образное основание, эмоциональное переживание) (Didkovskaya, 2000; Leontyeva, 2003; Zhakina, 2003). Данные исследовательские мероприятия позволят определить закономерности репрезентации феноменов «память» и «время» данными глагольными единицами.

\section{Результаты}

В рамках выделенного парадигматического подмножества ГКП ключевые слова с семантическим компонентом «время» (Vergangenheit - прошлое, Zeit время, Ewigkeit - вечность, Gegenwart - настоящее) отличаются значительным синтагматическим потенциалом, образуя в совокупности $1 / 5$ всех ГКП, использующихся в германских СМИ для обозначения операций памяти, что указывает на важность соответствующих понятий (время и разные временные фрагменты) для ментальной и языковой репрезентации феномена «память». Внутренняя структура организации данного подмножества онтологически обусловлена, включает подгруппы ЛЕ, обозначающих основные процессы памяти:

\section{ВОСПРОИЗВЕДЕНИЕ ИНФОРМАЦИИ}

Gegenwart (настоящее): die Gegenwart einholen (logDice 6.0) - (о прошлом) настигнуть настоящее / настигнуть в настоящем; in die Gegenwart zurückzuholen (logDice 6,5) - вернуть в настоящее; in die / jemandes Gegenwart hineinragen (logDice 6,6) - возникать в настоящем / вторгаться в настоящее; in die Gegenwart holen (logDice 1,5) - (букв.) привнести / принести в настоящее;

Zeit (время): (die) Zeit / Zeiten beschwören (logDice 5.06) - (букв. заклинать, звать, призывать) воскрешать время / времена; (der) Zeit / (den) Zeiten nachtrauern (logDice 5.8) - плакать, горевать по времени / временам; die Zeit holt jemanden ein (logDice 3.87) - время настигает, застает кого-то; sich in die Zeit / Zeiten zurückwünschen (logDice 4.2) - желать вернуться во время / времена; jemanden / sich in die / eine Zeit zurückversetzen (logDice 6.38) - кого-то / себя самого возвращать во время; sich nach den Zeiten zurücksehnen (logDice 7.77) тосковать по временам / хотеть вернуться во времена; sich in die (alten) Zeiten zurückträumen (logDice /2.92) - мечтать вернуться в (былье) времена; auf die Zeit / Zeiten zurückblicken (logDice 3.69) - оглядываться на время / времена; in die Zeit / Zeiten zurückgehen (logDice 4.39) - возвращаться во время / времена;

XLinguae, Volume 12, Issue 3, June 2019, ISSN 1337-8384, eISSN 2453-711X 
Vergangenheit (прошлое): in die Vergangenheit schauen (logDice 4.8) - смотреть в прошлое; in der Vergangenheit wühlen (logDice 4.97) - копаться в прошлом; die Vergangenheit holt jemanden ein (logDice 10.39) - прошлое настигает кого-либо; die Vergangenheit lässt etw. / jemdn. nicht / nie los (logDice 7.66) - прошлое не отпускает кого-либо; die Vergangenheit lehrt (jemanden) (logDice 7.3) - прошлое учит (кого-либо); die Vergangenheit lebt auf (logDice 6.34) - прошлое оживает; die Vergangenheit kehrt wieder (logDice 5.67) - прошлое возвращяается; die Vergangenheit hängt jemandem an (logDice 4.89) - прошлое довлеет над кем-либо, властно над кем-либо; die Vergangenheit rückt (jemandem) nah /näher / in die Nähe (logDice 4.66) - прошлое вновь возврашается (букв. приближается, становится близким); die Vergangenheit kehrt zurück (logDice 4.59) - прошлое возвращзается; die Vergangenheit kommt zurück (logDice 4.37) - прошлое приходит снова / назад; die Vergangenheit taucht auf (logDice 3.9) - прошлое вспльвает; die Vergangenheit aufarbeiten (logDice 9.77) - прорабатывать прошлое; die Vergangenheit beschwören (logDice 7.62) - (букв. заклинать, звать, призывать) воскрешать прошлое; der Vergangenheit nachtrauern (logDice 7.09) - горевать по прошлому; die Vergangenheit rekonstruieren (logDice 6.71) - восстанавливать, реконструировать прошлое; die Vergangenheit verarbeiten (logDice 6.1) перерабатывать прошлое; die Vergangenheit heraufbeschwören (logDice 6.05) воскрешать прошлое; die Vergangenheit aufrollen (logDice 5.2) - (букв. раскатьвать, разворачивать как ковер, рулон) прокрутить / обсудить прошлое; die Vergangenheit ausgraben (logDice 5.27) - раскопать, откопать (вытащить на свет божий) прошлое; der Vergangenheit nachhängen (logDice 5.21) - предаваться воспоминаниям о прошлом, отдаваться прошлому, погрузиться в прошлое; die Vergangenheit glorifizieren (logDice 5.11) прославлять прошлое; die Vergangenheit enthüllen (logDice 5.1) - разоблачать прошлое; sich der Vergangenheit stellen (logDice 5.08) - подчиняться прошлому; die Vergangenheit beschönigen (logDice 4.83) - приукрашать прошлое; die Vergangenheit verharmlosen (logDice 4.77) - недооченивать, сглаживать прошлое, представлять его в более безобидном виде; die Vergangenheit zurückrufen (logDice 4.69) - (букв. звать, призывать назад) возвращать, воскрешать прошлое; aus der / jemandes Vergangenheit lernen (logDice 6.23) учиться у прошлого, извлекать уроки из прошлого; auf Vergangenheit zurückblicken (logDice 5.76) - оглядываться на прошлое; in Vergangenheit blicken (logDice 5.72) - смотреть назад, в прошлое; in die Vergangenheit reisen (logDice 5.35) - (букв. путешествовать) отправляться, возвращаться в прошлое; in Vergangenheit leben (logDice 5.31) - жить в прошлом / прошльм.

УТРАТА ИНФОРМАЦИИ

Zeit (время): die Zeit heilt (alle Wunden / Wunden) (logDice 7.11) - время лечит (все раны / paнbl);

Vergangenheit (прошлое): die Vergangenheit ruht (logDice 6.46) - прошлое покоится; die Vergangenheit verblasst (logDice 5.04) - прошлое блекнет; die Vergangenheit rückt (jemandem) ferner / weg / in die Ferne (logDice 4.66) прошлое уходит в даль, отдаляется; die Vergangenheit bewältigen (logDice 9.21) - преодолевать прошлое; die Vergangenheit verdrängen (logDice 7.89) вытеснять прошлое; die Vergangenheit ruhen lassen (logDice 7.33) оставить в покое / покоиться прошлое; die Vergangenheit abschütteln (logDice 7.03) стряхнуть прошлое (букв. как пыль, мусор); die Vergangenheit verleugnen (logDice 7.1) - отрицать прошлое / отрекаться от прошлого; die Vergangenheit abstreifen (logDice 6.9) - (букв. сбрасывать как змея кожу, снимать как перчатки, чулки и пр.) сбрасывать прошлое; die Vergangenheit überwinden (logDice 6.17) - преодолевать, побеждать прошлое; die Vergangenheit begraben (logDice 6.14) - похоронить прошлое; der Vergangenheit entfliehen (logDice 5.86) 
- бежать от прошлого; die Vergangenheit entsorgen (logDice 5.9) - (букв. сдавать в утиль) устранять прошлое; der Vergangenheit entkommen (logDice 5.61) - убегать от прошлого; die Vergangenheit vertuschen (logDice 5.59) затушевывать, заминать прошлое; die Vergangenheit ausblenden (logDice 5.41) стирать, удалять прошлое; der Vergangenheit abschwören (logDice 5.39) отрицать, отвергать прошлое; die Vergangenheit unter den Teppich kehren (logDice 5.35) - загонять / прятать прошлое под ковер; die Vergangenheit loswerden (logDice 5.25) - избавляться от прошлого; die Vergangenheit tilgen (logDice 5.05) - (букв. погасить как долг) стирать, уничтожать прошлое; der Vergangenheit entrinnen (logDice 4.91) - бежать от прошлого; die Vergangenheit verbergen (logDice 4.64) - прятать прошлое; mit der / jemandes Vergangenheit brechen (logDice 6.15) - порвать c прошльм; sich von der / jemandes Vergangenheit distanzieren (logDice 5.29) - отдаляться, дистаниироваться от прошлого; sich von der / jemandes Vergangenheit lösen (logDice 5.1) освобождаться от прошлого.

\section{ХРАНЕНИЕ ИНФОРМАЦИИ}

Zeit (время): (die) Zeit / Zeiten kennen (logDice 5.63) - помнить / хранить в памяти время / времена;

Vergangenheit (прошлое): die Vergangenheit lastet auf etw. / jemandem (Dat.) (logDice 7.32) - прошлое давит / лежит грузом на ком-то / чем-то; die Vergangenheit lebt fort (logDice 6.29) - прошлое живет дальше; die Vergangenheit lebt weiter (logDice 4.79) - прошлое живо, продолжает жить; die Vergangenheit bewahren (logDice 4.61) - хранить прошлое; die Vergangenheit konservieren (logDice 5.73) - консервировать прошлое ЗАПЕЧАТЛЕНИЕ ИНФОРМАЦИИ

Zeit (время): die Zeit festhalten (logDice 4.41) - удерживать, фиксировать, хранить время;

Ewigkeit (вечность): etwas / jemanden für die Ewigkeit festhalten (logDice 4.81) что-то / кого-то сохранить для вечности; für die Ewigkeit bestimmt sein (logDice 4.55) - быть предназначенным для вечности; etw. für die Ewigkeit bewahren (logDice 4.53) - что-то сохранить для вечности; in Ewigkeit eingehen (logDice 4.33) - войти в вечность.

Наиболее лексически представлены в анализируемом множестве ситуации воспроизведения $(54,87 \%)$ и утраты $(31,72 \%)$ объекта в памяти, наименее ситуации хранения $(7,32 \%)$ и запечатления $(6,09 \%)$ объекта в памяти, что отражает значимость понятий о времени для ментальных и языковых репрезентаций соответствующих процессов памяти в изучаемой лингвокультуре. При этом наиболее активным при образовании ГКП является КС Vergangenheit - прошлое (75,61\% всех отобранных ГКП), что указывает на превалирующую репрезентацию в языке реверсивного характера операций памяти; далее следуют КС Zeit - время (14,63\%; относительно высокая активность КС объясняется, по-видимому, широким экстенсионалом значения данной ЛЕ, т. е. способностью обозначать разные отрезки временного континуума и весь континуум), Gegenwart - настоящее (4,88\%) и Ewigkeit вечность $(4,88 \%)$.

Понятие, обозначаемое КС Zeit (время), оказывается релевантным для репрезентации всех операций памяти - воспроизведения, запечатления, хранения и утраты информации в памяти (во всех подгруппах ГКП это - второе по частотности КС после Vergangenheit или Ewigkeit). КС Ewigkeit (вечность) образует коллокации, используемые исключительно для обозначения ситуаций запечатления объекта в памяти, характеризуя прочность, длительность сохранения информации; КС Gegenwart (настоящее) релевантно только при 
обозначении ситуаций воспроизведения объекта в памяти, указывая на присутствие воспроизводимого объекта «здесь и сейчас», его актуальность на данный момент. КС Vergangenheit (прошлое) образует наибольшее количество ГКП, обозначающих все процессы памяти кроме запечатления объекта в памяти, что обусловлено проспективным характером запоминания.

Большая часть анализируемых ГКП представляют собой словосочетания с простой структурой, предполагающей одну связь (между грамматически опорным коллокатом и КС), например: die Vergangenheit abstreifen стряхивать прошлое, die Vergangenheit tilgen - уничтожать, стирать прошлое, in Ewigkeit eingehen - войти в вечность, (der) Zeit / (den) Zeiten nachtrauern - горевать по времени / временам, (die) Zeit / Zeiten beschwören воскрешать время / времена. Коллокации со сложной структурой, предполагающей дополнительную связь / связи, немногочисленны, например: die Vergangenheit unter den Teppich kehren - загонять / прятать прошлое под ковер.

В изучаемом множестве ГКП присутствуют: 1) (преобладающие) внутренне и внешне непереходные коллокации (КС выполняет синтаксическую роль субъекта, дополнения в дательном падеже, обстоятельства, выражаемого КС в составе предложной группы) - 48,78\%; 2) (высоко частотные) внутренне переходные (с прямым дополнением в качестве компонента коллокации) $40,24 \%$; 3) (значительно менее частотные) внешне переходные коллокации, требующие распространение прямым дополнением в контексте (10,98\%).

При номинации ситуаций воспроизведения объекта в памяти выявлены следующие закономерности:

значительно преобладают внутренне и внешне непереходные ГКП (например, (der) Zeit / (den) Zeiten nachtrauern - горевать по времени / временам; auf die Zeit / Zeiten zurückblicken - оглядьваться на время / времена; in der / jemandes Vergangenheit wühlen - копаться в прошлом; die Vergangenheit taucht auf - прошлое вспльвает; in Vergangenheit leben - жить в прошлом / прошлым);

частотными являются также внутренне переходные ГКП (например, (die) Zeit / Zeiten beschwören - (букв. звать, призывать) воскрешать время / времена; die Vergangenheit ausgraben - раскапьвать / откапьвать прошлое; die Vergangenheit zurückrufen - (букв. звать назад) возвращать / воскрешать прошлое).

При обозначении запечатления объекта одинаково релевантны внешне переходные (например, etwas / jemanden für die Ewigkeit festhalten - coxранить для вечности; für die Ewigkeit bewahren - хранить, беречь для вечности) и внутренне и внешне непереходные ГКП (например, in Ewigkeit eingehen - войти в вечность).

При обозначении утраты и хранения объекта в памяти почти одинаково частотны внутренне переходные ГКП (например, die Vergangenheit verdrängen вытеснять прошлое; die Vergangenheit tilgen - уничтожать прошлое; die Vergangenheit konservieren - консервировать прошлое; (die) Zeit / Zeiten kennenпомнить время / времена) и внутренне и внешне непереходные ГКП (например, die Vergangenheit verblasst - прошлое блекнет; der Vergangenheit entfliehen бежать от прошлого; mit der / jemandes Vergangenheit brechen - порвать c прошльм; die Vergangenheit lebt fort-nрошлое живет дальше).

Большая часть коллокаций $(75,61 \%$ от общего количества ГКП) обнаруживает признак «субъектность», то есть описывает операции памяти как связанные с фрагментами временного континуума действия / состояния субъекта: например, in Vergangenheit leben - жить в прошлом / прошльмм, auf die Zeit / Zeiten zurückblicken - оглядываться на время / времена, die Zeit 
festhalten - удерживать, сохранять время, etw. für die Ewigkeit bewahren хранить, беречь для вечности, sich in die Zeit zurückwünschen - хотеть вернуться во время, auf Vergangenheit zurückblicken - смотреть на / в прошлое). При этом превалируют односубъектные ГКП, а именно, предусматривающие одушевленный субъект.

Около половины всех анализируемых ГКП являются субъектнообъектными $(47,56 \%)$, т.е. описывают операции памяти как действия субъекта, направленные на объект: например, (die) Zeit / Zeiten beschwören - воскрешать время / времена, die Vergangenheit begraben - (по)хоронить прошлое, die Zeit festhalten - сохранять, фиксировать время, etwas / jemanden für die Ewigkeit festhalten - что-то / кого-то сохранить для вечности, увековечить. Менее представлены в общей выборке несубъектные ГКП (29,25\%), обозначающие процессы памяти как непроизвольные, неконтролируемые субъектом, что обеспечивается посредством персонификации временных фрагментов или объектов операций памяти: например, die Vergangenheit lebt auf - nрошлое оживает, die Vergangenheit hängt jemandem an - (букв. висит подвешенным, прицеплено) прошлое тяготеет над кем-то).

В подгруппах ГКП, называющих воспроизведение и утрату объектов в памяти, распределение приведенных параметров аналогично. В подгруппах «хранение объекта в памяти» и «запечатление объекта в памяти» субъектные, субъектно-объектные, несубъектные ГКП одинаково представлены.

Таким образом, воспроизведение и утрата объектов в памяти репрезентируются, преимущественно, как действия, инициируемые и выполняемые самим субъектом, в половине случаев, направленные на объект. Хранение и запечатление объекта в памяти описываются либо как действие субъекта, либо как непроизвольные, неконтролируемые процессы.

Функции падежных форм именного компонента отражают способы осмысления временных фрагментов при репрезентации операций памяти. КС указывают, преимущественно, на объект $(51,92 \%)$, реже - на субъект $(18,27 \%)$, место (16,35\%) или косвенный объект - адресат $(13,46 \%)$ действия:

- Gegenwart (настоящее) при репрезентации операций памяти, большей частью, представляется как место (75\%), гораздо реже - как объект (25\%) действия, не выступает в качестве косвенного объекта или субъекта.;

- Zeit (время), чаще всего, указывает на объект $(43,75 \%)$ и место $(31,25 \%)$, реже - на косвенный объект и субъект (по 12,5\%) действия.

- Vergangenheit (прошлое) выступает, прежде всего, в качестве объекта $(57,5 \%)$, реже - в роли субъекта $(21,25 \%)$, редко - в функции косвенного объекта, то есть, адресата (11.25\%) и места (10\%) действия.

Ewigkeit (вечность) соотносится с косвенным объектом - адресатом (75\%), реже - с местом (25\%) действия, не выступает в роли субъекта или объекта действия.

КС характеризуются разной активностью при образовании именных серий, под которыми мы понимаем ряды ГКП с серийным КС, имеющие схожие схемы семантизации. Наибольшее количество серий образует КС Vergangenheit прошлое (16 серий), остальные анализируемые КС (Gegenwart-нacтоящеe, Zeit - время, Ewigkeit - вечность) образуют по одной серии, что отражает разную значимость называемых понятий для описания процессов памяти в изучаемой лингвокультуре.

Наибольшее количество именных серий образуют ГКП, обозначающие воспроизведение объекта в памяти (11 серий), наименьшее - ГКП, называющие запечатление объекта в памяти (1 серия). Наличие множества серий с именными компонентами указывает на важность для носителей немецкого языка

XLinguae, Volume 12, Issue 3, June 2019, ISSN 1337-8384, eISSN 2453-711X 
уточнения и четкой дифференциации признаков процесса / действия / состояния с помощью семантически близких глаголов.

Структурно-семантическое моделирование позволило выявить схематизированные инварианты соотношения формальных и семантических признаков ГКП, что подтверждает регулярность корреляций и семантических переносов, лежащих в основе сверхсловной номинации.

Проиллюстрируем выявленные структурно-семантические модели.

ВОСПРОИЗВЕДЕНИЕ ИНФОРМАЦИИ

in die Gegenwart zurückzuholen / holen - глаголы с общим значением «добывать, доставать, приносить» + абстрактное существительное в Nom. Модель: ПЕРЕМЕЩАТЬ КУДА (инициируемое субъектом воспоминание);

der Vergangenheit / (der) Zeit / (den) Zeiten nachtrauern - глагол с значением «горевать, оплакивать, тосковать» + абстрактное существительное в Akk. Модель: ЖЕЛАТЬ (вернуть) ЧТО (инициируемое субъектом воспоминание);

die Vergangenheit / die Zeit holt jemanden ein; die Vergangenheit lässt etw. I jemdn. nicht / nie los; die Vergangenheit hängt jemandem an - глаголы с общим значением «не отпускать, настигать, цепляться» + абстрактное существительное в Nom. + одушевленное существительное / личное местоимение в Akk. Модель: ПРЕСЛЕДУЕТ / ЗАХВАТЫВАЕТ ЧТО КОГО (непроизвольное воспоминание);

sich in die / eine Zeit zurückwünschen / zurückversetzen / zurückträumen глаголы с общим значением «жаждать, тосковать, хотеть вернуться» + предлог с пространственным значением + абстрактное существительное в Akk., указывающее на конечную цель. Модель: ЖЕЛАТЬ снова КУДА (инициируемое субъектом воспоминание);

in die Zeit / Zeiten zurückgehen; in die Vergangenheit reisen; in die / jemandes Gegenwart hineinragen - глаголы с общим значением «двигаться, передвигаться, перемещаться» + предлог с пространственным значением + абстрактное существительное в Akk., указывающее на конечную цель. Модель: ПЕРЕМЕЩАТЬСЯ КУДА (инициируемое субъектом воспоминание);

die Vergangenheit kehrt wieder / kehrt zurück / kommt zurück / taucht auf / rückt (jemandem) nah /näher / in die Nähe - глаголы с общим значением «возвращаться, продвигаться, появляться, всплывать» + абстрактное существительное в Nom. (+ предложная группа: предлог с пространственным значением + наречие / абстрактное существительное в Akk., конкретизирующее направление). Модель: (вновь) ПОЯВЛЯЕТСЯ ЧТО (непроизвольное воспоминание);

die Vergangenheit aufarbeiten / verarbeiten / glorifizieren / beschönigen / verharmlosen - глагол с общим значением «изменять, модифицировать, менять» + абстрактное существительное в Akk. Модель: ИЗМЕНЯТЬ ЧТО (инициируемое субъектом воспоминание);

(die) Zeit / Zeiten / die Vergangenheit beschwören / heraufbeschwören; die Vergangenheit zurückrufen - глагол с общим значением «звать» + абстрактное существительное в Akk. Модель: ЗВАТЬ ЧТО (инициируемое субъектом воспоминание);

in die Vergangenheit schauen / blicken; auf Vergangenheit / auf die Zeit / Zeiten zurückblicken - глагол с общим значением «смотреть» + предложная группа (пространственный предлог + абстрактное существительное в Akk., конкретизирующее направление, цель). Модель: СМОТРЕТЬ КУДА (инициируемое субъектом воспоминание);

sich der Vergangenheit stellen; der Vergangenheit nachhängen - глагол с общим значением «подчиняться, отдаваться» + абстрактное существительное в Dat. Модель: БЫТЬ ОХВАЧЕННЫМ / ЗАХВАЧЕННЫМ ЧЕМ (инициируемое субъектом воспоминание); 
die Vergangenheit ausgraben / enthüllen / aufrollen / rekonstruieren - глаголы с общим значением «делать воспринимаемым, доступным, используемым» + абстрактное существительное в Akk. Модель: ДЕЛАТЬ ДОСТУПНЫМ / ПРИГОДНЫМ ДЛЯ ИСПОЛЬЗОВАНИЯ ЧТО (инициируемое субъектом воспоминание);

in / in der / jemandes Vergangenheit wühlen / leben - глаголы со значением «совершать действия, быть активным» + предлог с пространственным значением («место») + абстрактное существительное в Dat., указывающее на место. Модель: БЫТЬ АКТИВНЫМ ГДЕ (инициируемое субъектом воспоминание).

\section{УТРАТА ИНФОРМАЦИИ}

die Vergangenheit verdrängen / abschütteln / abstreifen / begraben / entsorgen / vertuschen / ausblenden / unter den Teppich kehren / tilgen / verbergen / loswerden глагол с общим значением «уничтожать, вытеснять, удалять» + абстрактное существительное в Akk. Модель: УДАЛЯТЬ ЧТО (инициируемое субъектом забывание);

der Vergangenheit entfliehen / entkommen / entrinnen - глагол с общим значением «удаляться, убегать, избегать» + абстрактное существительное в Dat. Модель: УДАЛЯТЬСЯ ОТ ЧЕГО (инициируемое субъектом забывание);

sich von der / jemandes Vergangenheit distanzieren / lösen - возвратный глагол со значением «освобождаться, отгораживаться, отмежёвываться» + предложная группа (предлог von, используемый при обозначении объектаисточника чего-либо, + абстрактное существительное в Dat.). Модель: ОТДЕЛЯТЬСЯ ОТ ЧЕГО (инициируемое субъектом забывание);

die Vergangenheit rückt (jemandem) ferner / weg / in die Ferne - глагол с общим значением «перемещаться, пододвигаться» + абстрактное существительное в Nom. + наречие с пространственным значением / предложная группа (пространственный предлог со значением направления + абстрактное существительное в Akk., указывающее на конечный пункт перемещения). Модель: ПЕРЕМЕЩАЕТСЯ ЧТО КУДА (непроизвольное забывание);

die Vergangenheit bewältigen / überwinden - глагол с общим значением «преодолевать, осиливать, побеждать, побороть» + абстрактное существительное вAkk. Модель: ПРЕОДОЛЕВАТЬ ЧТО (инициируемое субъектом забывание);

die Vergangenheit verleugnen / ruhen lassen - глагол с общим значением «отвергать, отрицать, оставлять» + абстрактное существительное в Akk. Модель: ОСТАВЛЯТЬ ЧТО (инициируемое субъектом забывание).

ХРАНЕНИЕ ИНФОРМАЦИИ

die Vergangenheit lebt fort / lebt weiter - глагол со значением «жить, быть, существовать дальше» + абстрактное существительное в Nom. Модель: ПРОДОЛЖАЕТ БЫТЬ ЧТО (непроизвольное хранение информации);

die Vergangenheit bewahren / konservieren; die Zeit festhalten - глаголы со значением «хранить, сохранять, удерживать» + абстрактное существительное в Akk. Модель: ХРАНИТЬ / СОХРАНЯТЬ ЧТО (инициируемые субъектом запоминание, каузация запоминания).

\section{ЗАПЕЧАТЛЕНИЕ ИНФОРМАЦИИ}

für die Ewigkeit festhalten / bewahren - глагол со значением «удерживать, фиксировать» + предложная группа: предлог für + абстрактное существительное в Akk. Модель: ДЕРЖАТЬ / УДЕРЖИВАТЬ ДЛЯ ЧЕГО (инициируемые субъектом запоминание, каузация запоминания).

XLinguae, Volume 12, Issue 3, June 2019, ISSN 1337-8384, eISSN 2453-711X 
Инициируемое субъектом воспроизведение объекта в памяти описывается ГКП немецкого языка как движение субъекта воспоминания (по отношению к объекту - временному фрагменту); перемещение субъектом объекта воспоминания (по отношению к временному фрагменту); действие субъекта над объектом - временным фрагментом (с целью вернуть его, сделать его другим или доступным); активность субъекта в неком пространстве, образуемом временным фрагментом; состояние субъекта в результате воздействия объекта (временной фрагмент).

Непроизвольное воспоминание представляется как действие / воздействие активного объекта (временной фрагмент) на субъекта операции памяти; как движение активного объекта (временного фрагмента) в пространстве памяти.

Инициируемое субъектом забывание репрезентируется как перемещение активного субъекта операции памяти по направлению от объекта (временного фрагмента); действие субъекта над объектом - временным фрагментом (с целью его удаления, уничтожения).

Непроизвольное забывание описывается ГКП как передвижение активного объекта (временного фрагмента) по отношению к субъекту операции памяти (в направлении от него).

Инициируемое субъектом хранение объекта в памяти представлено как действие субъекта над объектом.

Непроизвольное хранение изображается как состояние активного объекта (временного фрагмента).

Инициируемое субъектом запоминание изображается как действие субъекта над объектом запоминания (в интересах адресата - временного фрагмента).

Соответственно, фрагменты временного континуума могут интерпретироваться как активная, самостоятельная сущность (субъект / источник воздействия, субъект перемещения, субъект состояния, адресат действия); как объект, над которым осуществляется действие; как пространство действия / перемещения. Анализ тематических кодов (сферы отождествления называемых операций и элементов мнемических ситуаций, отражающие мотивирующую сверхсловную номинацию концептуальную интеграцию физической и ментальной сфер) подтверждает сделанные наблюдения. Релевантными для исследуемого множества тематическими кодами являются предметный - 39,02\%; персонифицирующий - 36,59\%; пространственный $24,39 \%$.

Прагматический компонент значения ГКП указывает на амбивалентное ценностное отношение к памяти и времени, раскрывающееся в ассоциируемых с ними образах.

Настоящее репрезентируется как некое, вполне определенное, значимое для субъекта пространство, в которое можно и нужно вернуть, переместить некий объект, где нечто может внезапно появиться; как живое существо, которое можно догнать, настигнуть.

Вечность при описании мнемических ситуаций репрезентируется как некое место, помещение, в которое можно войти и остаться там; как некое лицо, которому должен принадлежать объект, для которого он удерживается и хранится.

Время представляется в качестве живого лица, которого следует опасаться (потому что оно может настигнуть) или на которого можно рассчитывать, в котором нуждаются (потому что оно может исцелить), знакомое или близкое (которое можно позвать, по которому можно горевать или которое когда-то знал); как объект, который хочется еще раз увидеть, можно удерживать, не выпускать из рук; как приятное, значимое место (в которое хочется и можно вернуться). 
Прошлое в контексте разных процессов памяти предстает как некое существо, которое способно оживать, внезапно появляться, приближаться или удаляться, исчезать; как некое лицо - важное или нужное (например, мудрый учитель), близкое / родное / знакомое (по которому можно тосковать, которого можно оплакивать, звать, желать вернуть, похоронить, с которым возможно порвать отношения), опасное / чужое / неприятное (например, враг, которого нужно победить, от которого следует спасаться, бежать, который может настигать и не оставлять в покое, или негодяй, которого нужно разоблачить), известное своими великими делами (например, герой, которого можно прославлять); как неконтролируемая сила, которой субъект подчиняется или противостоит; как место, в которое можно отправляться, заглянуть ненадолго, многократно возвращаться, в котором можно жить, искать что-то; предмет или вещь, которая может испортиться, утратить свои свойства, которую возможно хранить, переделать, привести в прежнее состояние, откопать, спрятать, замаскировать, отодвинуть, оставить где-либо, уничтожить, стряхнуть как мусор, от которой можно избавиться, освободиться, отказаться; как тяжельй груз или источник мудрости и опьыта.

Таким образом, ГКП немецкого языка отражают амбивалентное ценностное отношение к памяти в ее сопряженности со временем (нечто нужное, важное, достойное или лишнее, мешающее, недостойное; неконтролируемое или подвластное человеку; дающее убежище или опасное; приятное или навязчивое, неприятное; изменчивое или постоянное).

\section{Выводы}

Выполненный анализ позволил сделать следующие выводы относительно лексико-семантической репрезентации памяти и ее взаимосвязи с понятием «время» посредством ГКП, функционирующих в германских СМИ.

Структура внутренней организации описываемого лексико-семантического подмножества единиц (ГКП) включает подгруппы, коррелирующие с основными процессами памяти. Исследуемые ГКП обладают высоким синтагматическим потенциалом, что указывает на значимость понятия «время» для ментальной и языковой репрезентации памяти. Понятие о временных фрагментах оказывается наиболее релевантным для лексического представления ситуации воспроизведения и утраты объекта в памяти, наименее - для ситуации хранения и запечатления объекта в памяти.

Трансформация отвлеченности именного (становится более конкретным) и глагольного (становится более абстрактным) компонентов обусловливается лежащей в основе номинации концептуальной интеграцией физической и ментальных сфер, отражается во внутренней форме коллокаций, определяет синтагматические характеристики компонентов ГКП и самих ГКП.

В семантике ГКП находят отражение признаки базовых элементов соответствующих ситуаций (субъект, объект, процесс); значимым компонентом реализуемой ГКП языковой модели памяти выступает локализация. Значения ГКП содержат указания на следующие дифференциальные признаки обозначаемых операций памяти: наличие / отсутствие каузации; инициация субъектом / непроизвольность; временные параметры; интенсивность; отсутствие / наличие дополнительной обработки объекта / сопровождающего действия / эмоциональной реакции; признаки объекта; определенная сенсорная модальность.

КС с семантическим компонентом «время» (Vergangenheit, Gegenwart, Zeit, Ewigkeit, обозначающие фрагменты временного континуума / весь континуум в целом) характеризуются различным семантическим потенциалом. КС

XLinguae, Volume 12, Issue 3, June 2019, ISSN 1337-8384, eISSN 2453-711X 
Vergangenheit (прошлое) акцентирует ретроспективный характер, КС Gegenwart (настоящее) - интенционально обусловленную актуальную значимость, КС Zeit (время) - потенциальную направленность на любую произвольно вычленяемую часть континуума, КС Ewigkeit (вечность) - проспективность или потенциально вневременной характер памяти.

Наибольшее лексическое представление в немецком языке получает реверсивный характер операций памяти, что отражается в наивысшей активности КС Vergangenheit (прошлое) при образовании ГКП (3/4 всех ГКП); далее в порядке убывания активности следуют КС Zeit (время), Gegenwart (настоящее) и Ewigkeit (вечность). При этом понятие «Zeit» релевантно для описания всех операций памяти; понятие «Vergangenheit» - всех, кроме запоминания объекта; понятие «Ewigkeit» - только для запечатления; понятие «Gegenwart» - только для воспроизведения объекта в памяти.

Большая часть ГКП - словосочетания с простой структурой. Почти одинаково частотны внутренне-внешне непереходные и функционирующие как синтагма внутренне переходные ГКП. Анализируемые ГКП, преимущественно, описывают операции памяти как связанную с фрагментами временного континуума активность субъекта, в половине случаев - как направленные на объект действия субъекта; 1/3 ГКП описывают операции памяти как непроизвольные, неконтролируемые процессы.

Функции падежных форм КС указывают на превалирующее представление фрагментов временного континуума и самого континуума в мнемических ситуациях как объекта действия (> 1/2), реже - как субъекта, места или адресата действия (с примерно одинаковой релевантностью). При этом «время» (Zeit) и «прошлое» (Vergangenheit), преимущественно, мыслятся как объект (прим. 1/2 ГКП с соответствующими КС); «настоящее» (Gegenwart), большей частью, - как место действия (3/4); «вечность» (Ewigkeit) - как адресат (3/4); при этом «настоящее» (Gegenwart) и «вечность» (Ewigkeit) интерпретируются как менее активные, не выступают в качестве субъекта действия.

Парадигматическое объединение ГКП включает именные серии, свидетельствующие о важности для носителей немецкого языка лексикализованной дифференциации конкретных признаков процессуальной составляющей посредством семантически близких глаголов. Наибольшее количество серий образует КС Vergangenheit (прошлое), что отражает особую значимость называемого фрагмента временного континуума для ментальной репрезентации и оязыковления процессов памяти в немецкой лингвокультуре.

Исследуемые ГКП - моделируемые единицы. Выявленные структурносемантические модели ГКП свидетельствуют, что операции памяти в их связи с понятием «время» описываются как движение субъекта (по отношению к объекту - временному фрагменту) или движение активного объекта (временного фрагмента) в пространстве памяти; перемещение субъектом объекта операции памяти (по отношению к временному фрагменту) или самого временного фрагмента; иное действие субъекта над объектом - временным фрагментом; активность субъекта в неком пространстве, образуемом временным фрагментом; воздействие активного объекта (временного фрагмента) на субъекта; состояние субъекта операции памяти в результате воздействия объекта (временного фрагмента) или состояние активного объекта - временного фрагмента. Таким образом, фрагменты временного континуума интерпретируются в рамках мнемических ситуаций как активная, самостоятельная сущность (субъект / источник воздействия, субъект перемещения, субъект состояния, адресат действия); получают пассивную интерпретацию как объект или пространство действия / перемещения. Реализуемые при изучаемой сверхсловной номинации частотные тематические 
коды (предметный, персонифицирующий, пространственный) подтверждают данное наблюдение.

Прагматический компонент значения ГКП указывает на многообразие ассоциативных образов памяти и времени и амбивалентное ценностное отношение к памяти и времени. Функционально-семантический потенциал ГКП определяется их семантическими, структурными и синтагматическими характеристиками, в которых отражаются психологические, физиологические, временные аспекты памяти, взаимосвязи элементов психосферы человека.

\section{Bibliographic references}

ANOKHIN, P.K. - ANOKHIN, K.V. (2011) Osnovnyye polozheniya teorii funktsionalnykh sistem P.K. Available online: http:/www.medlinks.ru/sections.php?op=viewarticle\&artid=1357.

BADDELEY, A.D. 2007. Working memory, thought, and action. Oxford: Oxford University Press. ISBN-13: 9780198528012.

BAKIYEVA, G.A. 2001. Filosofskiy analiz fenomena sotsialnoy pamyati: diss. ... doktora filosofskikh nauk. St. Petersburg, $339 \mathrm{p}$.

BAUMEISTER F. - HASTINGS, S. 1997. Distortions of Collective Memory: How Groups Flatter and Deceive Themselves. In: Collective memory of political events: Social psychological perspectives. Lawrence Erlbaum Associates, pp. 277-294. ISBN13: 978-0805821826.

BERGSON, A.1992. Materiya i pamyat. vol. 1. Moscow: «Moskovskiy klub». pp. 157-316. ISBN 5-7642-0003-2.

BRAGINA, N.G. 2003. Pamyat i proshloye: Yazykovyye obraza. kulturnyye praktiki // Izvestiya Rossiyskoy akademii nauk, vol. 62, n. 5, pp. 3-13.

BYALEK, E. 2004. Kollokatsiya kak edinitsa perevoda // Cuadernos de Russistica Espanöla, n. 1, pp. 223-231.

DANEMAN, M. 1991. Working memory as a predictor of verbal fluency. In: Journal of Psycholinguistic Research, n. 20(6), pp. 445-464.

DIAS, M. 2010. Erinnerte Geschichten: individuelle Identität und kollektives Gedächtnis in „Am Beispiel meines Bruders“ und „Der Freund und der Fremde von Uwe Timm.“ In: Rhamenwechsel. Kulturwissenschaften. Würzburg: Königshausen \& Neimahn, pp. 265-275.

DIDKOVSKAYA, V.G. 2000. Sistemno-funktsionalnoye opisaniye frazeologicheskikh sochetaniy sovremennogo russkogo yazyka (na materiale glagolno-imennykh sochetaniy): avtoref. diss. ... doktora filologicheskikh nauk. St. Petersburg, $32 \mathrm{p}$.

DWDS - Digitales Wörterbuch der deutschen Sprache. Available online: http://www.dwds.de (data obrashcheniya 20.09.2018).

ELNITSKY, L. - MEL'CUK, I.A. 1984. Toward the lexicographic description of the cooccurrence of "parametric" lexemes in French and Russian. In: Lingvisticae Investigationes, vol. 8(2), pp. 269-284.

GAYSINA, R.M. 1982. K voprosu o spetsifike znacheniya glagola. // Izvestiya Rossiyskoy akademii nauk. Seriya Literatury i yazyka, vol. 41, n. 1, pp. 59-64.

GEYKEN, A. 2007.The DWDS corpus: A reference corpus for the German language of the 20th century. In: Fellbaum, Ch. (ed.) Collocations and Idioms: Linguistic, lexicographic, and computational aspects. London: Continuum Press, pp. 23-41.

HALBWACHS, M. 2007. Sotsialnyye ramki pamyati. Moscow: Novoye izdatelstvo, 348 p. ISBN 978-5-98379-088-9.

HAUSMANN, FJ. 1985. Kollokationen im deutschen Wörterbuch: ein Beitrag zur Theorie des lexicographischen Beispiels // Lexicographie und Grammatik. Tübingen: Max Niemeyer, pp. 118-129.

XLinguae, Volume 12, Issue 3, June 2019, ISSN 1337-8384, eISSN 2453-711X 
KEPPLER, A. 2001. Soziale Formen individuellen Erinnerns. Die kommunikative Tradierung von (Familien-) Geschichte // Das soziale Gedächtnis. Geschichte, Erinnerung, Tradierung. H. Welzer (Hrsg.). Hamburg, pp. 137-159.

KHOKHLOVA, M.V. 2010. Issledovaniye leksiko-sintaksicheskoy sochetayemosti v russkom yazyke s pomoshchyu statisticheskikh metodov (na baze korpusov tekstov): avtoreferat diss. ... kandidadata filol. nauk. St. Petersburg, 26 p.

KILGARRIFF, A. 2006. Collocationality (and how to measure it) // Proceedings of the Xllth Euralex International Congress. Torino: Universitä di Torino, pp. 997-1004.

LEONTYEVA, T.V. 2003. Intellekt cheloveka v zerkale russkogo yazyka: avtoreferat diss. ... kand. filol. nauk. Ekaterinburg, 24 p.

LINKE, A. 2005. Kulturelles Gedächtnis. Linguistische Perspektiven auf ein kulturwissenschftliches Forschungsfeld // Brisante Semantik. Neure Konzepte und Forschungsergebnisse einer kulturwissenschaftlichen Linguistik. Tübingen: Max Niemeyer Verlag, pp. 64-85. ISBN-13: 978-3484312593.

LÜBBE, H. 2003. Im Zug der Zeit : verkürzter Aufenthalt in der Gegenwart. Berlin: Springer, 454 p. ISBN 3-540-58122-7.

MANNING, C. - SCHUTZE, H. 2002. Collocations. In: Manning C., Schutze H. Foundations of Statictical Natural Language Processing, pp.151-189.

MCQUAID, S.D. 2017. Parading Memory and Re-member-ing Conflict: Collective Memory in Transition in Northern Ireland. In: International Journal of Politics, Culture and Society, vol. 30(1), pp. 23-41.

MÜLLER-FUNK, W. 2004. Zur Narrologie des kulturellen und kollektiven Gedächtnisses.In: Geschichtsdarstellung. Medien - Methoden - Strategien. Köln: Böhlau Verlag. pp. 145-167.

PETROVA A.A. - REBRINA L.N. 2016. Autobiographical memory: genesis, functioning, discursive implementation. In: Xlinguae, vol. 9, n. 2, pp. 11-36. ISSN 1337-8384.

PETROVIC S. - SNAJDER J. - BASIC B.D. - KOLAR M. 2006. Comparison of collocation extraction for document indexing. In: Journal of Computing and information technology. CIT 14, n. 4, pp. 321-327.

POPOV, V.P. - KRAYNYUCHENKO, I.V. 2009. Triyedinyy fundament Vselennoy. Informatsiya. vremya. prostranstvo // Akademiya trinitarizma. Moscow. URL://: http://www.trinitas.ru/rus/000/a0000001.htm/04.08.2010. (data obrashcheniya: 16.06.2010).

PRIGOGINE, I. -STENGERS, I. 1984. Order out of chaos: Man's new dialogue with nature. London: Heinemann. ISBN 0-553-34082-4.

REBRINA, L.N. - SHAMNE, N.L. - MILOVANOVA, M.V. - TERENTYEVA, E.V. 2017. Verbal Collocations of Memory: Functional-Semantic and Lexicographic Aspects. In: Proceedings of the 7th International Scientific and Practical Conference "Current issues of linguistics and didactics: The interdisciplinary approach in humanities" (CILDIAH). Advances in Social Science, Education and Humanities Research. Atlantis press, vol. 97, pp. 239-245.

WELZER, H. 2005. Das kommunikative Gedächtnis. Eine Theorie der Erinnerung. München: Verlag C.H. Beck. 260 p.

WYLEGAŁA, A. 2017. Managing the difficult past: Ukrainian collective memory and public debates on history. In: Nationalities Papers, pp. 1-18.

YAGUNOVA, E.V. - PIVOVAROVA, L.M. 2010. Priroda kollokatsiy v russkom yazyke. Opyt avtomaticheskogo izvlecheniya i klassifikatsii na materiale novostnykh tekstov. // NTI, Ser. 2, n. 6, pp. 30-40.

ZHAKINA, Yu.S. 2003. Protsessualnyye frazeologizmy subkategorii deyatelnosti: avtoreferat diss. ... kandidata filologicheskikh nauk. Kurgan, 23p. 
Words: 6549

Characters: 54347 (30,19 standard pages)

Prof. Dr. Larisa N. Rebrina, Dr. Sci.

Department of Germanic and Romance philology

Volgograd State University, Russia

100 Pr. Universitetskiy, 400062, Volgograd,

Russia

lnrebrina@volsu.ru 